\title{
ABUSO SEXUAL DE CRIANÇAS E ADOLESCENTES: TRAMA, DRAMA E TRAUMA $^{1}$
}

Vicente de Paula Faleiros ${ }^{2}$

\section{RESUMO}

Neste texto é abordada a questão do abuso sexual de crianças e adolescentes tanto como uma relação complexa de violência, segredo e cumplicidade intra-familiar como uma relação social inserida no imaginário social como trama de relações, drama social e trauma para os vitimizados. O artigo aponta também para a superação dessa violência, propugnando por um paradigma de pensamento e ação fundados na defesa dos direitos humanos, na apreensão da complexidade da questão da violência sexual e da sexualidade, na mudança das dinâmicas familiares e de seu contexto, e na construção de redes sociais.

PALAVRAS-CHAVE: Abuso sexual de crianças e adolescentes; Incesto; Violência sexual intrafamiliar; Superação da violência.

Neste texto vou abordar a questão da trama, do drama e do trauma do abuso sexual de crianças e adolescentes e referir-me também à rede de proteção a essas crianças e adolescentes. A discussão do problema, assim, está articulada à sua superação.

As situações de violência, muitas vezes, só são apresentadas a partir de seu ângulo traumático de dano ou prejuízo à vítima, ou como de denúncia, sem que se considerem seu desmonte, sua reparação ou sua prevenção. Para realizar esse triplo movimento têm papel fundamental tanto a família, como o estado e a sociedade. Inicialmente vou referir-me à família, depois tratarei da rede de proteção que envolve tanto a família, como o estado e a sociedade.

É impossível falar do tema da violência sexual sem nos referirmos à família, cuja configuração vem sofrendo mudanças rápidas no mundo contemporâneo, inserida que está no contexto e no processo histórico, ou seja nas complexas relações econômicas, políticas, sociais e culturais, incluindo as de etnia, raça e gênero. De acordo com uma visão dominante, a família tem por funções sociais, como processo dinâmico e não como um funcionalismo abstrato: a reprodução, a socialização, a internalização de valores, a educação e o desenvolvimento de seus membros. Essas dimensões consideradas básicas

\footnotetext{
${ }^{1}$ Texto revisado de uma palestra no $32^{\circ}$ aniversário do COMPP - Centro de Orientação Médico-Pedagógica em 13/11/2001.

${ }^{2}$ Assistente social, $\mathrm{PhD}$ em Sociologia, pesquisador associado da UnB e do CECRIA, autor e consultor. Serviço Social \& Saúde, Campinas, v. 2, n. 2, p. 65-82
} 
fazem da família uma instituição universal, mas com diferentes formas de organização ao longo da história e de acordo com diferentes culturas.

A família inscreve-se na história de cada povo, de cada cultura, como uma relação não só de reprodução da espécie e do indivíduo, mas também como agente articulador cultural e de socialização. É através da família que recebemos nossos nomes e sobrenomes, por exemplo, sou Faleiros, da família Faleiros, e sou, ao mesmo tempo, Vicente, o indivíduo Vicente, aqui e agora. Incorporo toda a trajetória de uma família e, ao mesmo tempo, sou individualizado, tenho uma identidade com meu nome próprio. Esse nome tem uma história social e familiar, e é designado social e familiarmente.

Nas histórias familiares, entretanto, as relações são contraditórias e, não raramente, se tornam conflituosas e violentas. Diddier- Weil afirma que ela é o "teatro de uma tragédia ${ }^{3}$, da qual cada um de nós é um ator seja como dominante ou dominado, assassino ou vítima" (DIDIER-WEILL, 1997, p. 17). Por serem contraditórias as relações sociais, a família é um lócus de exercício de poder, articulado nas sociedades patriarcais, ao poder do pai, mas onde há conflitos e violência e também apoio e cooperação. Assim, nas famílias, há disputas conscientes e inconscientes de interesses, de lugar, de nome, de preferências, de relação com o pai, com a mãe, não só do ponto de vista psicanalítico — o complexo de Édipo é um exemplo — , mas também do ponto de vista social e econômico, como as disputas por herança, por dinheiro ou pelo reconhecimento da família e dentro da própria família. Uma questão chave para se entender essa relação de poder familiar é a da relação de gênero, pela imposição ou reconhecimento do lugar do homem, do provedor, do macho, do forte em relação ao papel social atribuído à mulher de cuidadora, de nutriz, de responsável por afazeres domésticos. O questionamento desses papéis sociais internalizados também gera conflitos. O poder de "chefe" se exerce no domínio do outro, na submissão e no uso (abuso) do outro como servo, como objeto de prazer, como mandado, em relações que são consideradas "naturais" ou eternas. O questionamento do chefe é visto como desordem, rebelião, desobediência frente à qual se reforça a ameaça, a força, o castigo e principalmente a culpabilização e a punição. É a violência da manutenção da ordem, conforme Faleiros (2002).

\footnotetext{
${ }^{3}$ Freud dizia que "a essência da família é a de ser um assassinato". Serviço Social \& Saúde, Campinas, v. 2, n. 2, p. 65-82
} 
Assim, a família não é, em princípio, um lugar tranqüilo, embora seja também um espaço de harmonização, de ajuda, de confraternização, de afeto, de festa, de celebração, de apoio. Nem sempre as festas expressas em fotos com todos sorridentes traduzem todo o convívio familiar. A festa pode ser amargada por explosão de episódios tristes e violentos, como aparece em muitos filmes, em especial nas festas de casamento, aniversário e de fim de ano.

A família tem sido considerada secularmente pela sociedade como o espaço doméstico, em oposição ao espaço público. Esse espaço doméstico, o oikos em grego, o domus, ninho ou casa, tenda ou propriedade em latim, é, no imaginário e nas práticas sociais, o lugar das relações privadas, em oposição ao espaço público, lugar das relações da ágora, da cidade, da polis. Em Roma a família (no sentido clássico) compreendia também os servos que viviam sob o mesmo teto, sem que houvesse laços de sangue.

A vida privada da família foi vista como o lugar da não-cidadania, da ausência do público, da presença do poder privado, do chefe. A cidadania se exercia fora do recinto doméstico, do domínio familiar. Pensava-se assim, dicotomicamente, o pátrio poder e o poder público, numa ruptura entre o lugar privado e o lugar público.

O poder dentro da família, em geral, é centrado no chefe adulto e masculino. É tradição, em muitas culturas, que o poder dominante na família seja o do homem, o do provedor e também senhor e objeto de reverência ("com farinha pouca, meu pirão primeiro", diz o ditado). Todos sabem que na história de Esparta esse chefe tinha até o poder de eliminar aqueles que ele considerava incapazes de viver naquele círculo. Formase, no âmbito familiar, uma hierarquia de poderes das pessoas que obedecem diretamente ao chefe e executam suas ordens, como os filhos mais velhos.

Como exemplo, na Suécia, visitando uma instituição, vi uma estátua que mostrava, num pilar de cima para baixo, o homem, a mulher, a criança e o cachorro. Assim, nas escala de poder, em primeiro lugar aparece o homem, em segundo a mulher/mãe, em terceiro o filho (nesse caso único), e em último lugar, vem o cachorro, todos subordinados ao primeiro.

Esse poder familiar se exerce como poder privado e doméstico, por muito tempo sem interferência do público, das leis nessa esfera doméstica, acentuada com o liberalismo e as liberdades individuais. Os reis tinham certos privilégios de desalojar famílias, 
requisitar seus membros e usar mulheres, mas eram privilégios senhoriais, restritos ao senhor feudal sobre súditos (dominados) o que foi desmantelado na Revolução Burguesa.

$\mathrm{Na}$ estruturação do pátrio poder, reconhecido pelos códigos civis, consagrava-se o poder do adulto sobre a criança, o poder do homem sobre a mulher, o poder do macho sobre a fêmea, para usar uma denominação crua e cruenta.

Sendo a família hierarquizada, social, econômica e culturalmente, não podemos entender a violência intrafamiliar se não entendermos essas várias dimensões às quais estou me referindo aqui: os conflitos de interesses, a cultura, o poder machista, a esfera doméstica da família. É nesse contexto que vamos poder situar a violência intrafamiliar, cuja manifestação também é complexa e diversificada.

Existem vários tipos de violência intrafamiliar, desde a eliminação das pessoas até maus-tratos, ameaças, violência psicológica, violência sexual, chantagens, negligência, humilhações, designações de pessoas como doentes e incapazes. Nosso enfoque é violência sexual, do abuso sexual, do incesto. O incesto, na perspectiva de análise aqui adotada, está articulado à violência física, à transgressão social do tabu do incesto, à dominação do mais forte sobre o mais fragilizado.

As profundas mudanças por que passam as famílias na organização de seu formato organizacional como famílias monoparentais, com filhos de diferentes pais ou mães, com convivências e arranjos diferençados, com parceiros seqüenciais variados vão afetar as relações internas de cada arranjo, mas ainda os arranjos ainda se estruturam de acordo com um modelo profundamente enraizado de poder que pode até se manifestar em casais de homossexuais onde alguém pode exercer o papel de "mais forte", de dominador. Quando assinalamos, no quadro abaixo estamos visualizando esse padrão dominante e não um modelo estático.

A questão da violência sexual implica a consideração do contexto acima configurado e, ao mesmo tempo, a questão da sexualidade. Esta não se restringe, nas relações sociais, à dimensão reprodutiva. A reprodução humana é apenas uma das dimensões da sexualidade, que envolve o prazer, a relação de sedução, os valores, o consumismo e o desejo ou libido.

$\mathrm{Na}$ manifestação da violência sexual estão implicadas tanto as dimensões do poder intrafamiliar, do contexto social e cultural como a dimensão do (ab)uso ou manifestação da sexualidade humana nessas relações. A expressão da violência física está Serviço Social \& Saúde, Campinas, v. 2, n. 2, p. 65-82 
inserida na lógica da obediência, de obrigar o outro a fazer aquilo que o mais forte determina. A violência expressa uma ameaça à integridade do outro, uma negação do outro, uma imposição de si e de seu poder ao outro, e, contraditoriamente, ao mesmo tempo, como diz Hannah Arendt (1985, p. 20), uma falta de poder legítimo, da autoridade do convencimento e do reconhecimento e de regras pactuadas. Ela é o exercício de um poder que não se pratica de forma legitimada, socialmente estabelecida pelas normas do respeito mútuo. Alguns, diferentemente desta concepção, definem a violência como um excesso de poder.

A violência, no entanto, na ótica de Hannah Arendt (1985) é a "falta de poder legítimo", de autoridade, é o exercício de um poder que não se pratica de forma legitimada, socialmente estabelecida pelas normas do respeito mútuo.

Tanto a violência física, como a sexual, estão ligadas ao autoritarismo, ou seja, digamos assim — à falta do poder legítimo, e se exercita pela negação ou ameaça ao outro, para se impor através da força física ou do uso do poder moral ou legal. No quadro seguinte, cuja primeira versão apresentei no IX Congresso Brasileiro de Assistentes Sociais em Goiânia, em 1998, mostro as relações implicadas no abuso sexual intrafamiliar. Pode-se observar as implicações complexas e articuladas das dimensões do contexto cultural (etnia, gênero, raça), social (relações familiares), econômico (provedor), da sexualidade (sedução/culpabilização), do poder (força/segredo), psicológicas (medo, trauma).

Como se pode observar, as relações abusadoras implicam tramas das dimensões acima analisadas que se revertem em dramas para as vítimas, significativamente presentes em arranjos familiares autoritários, por sua vez implicando relações sociais divididas. O trauma se faz e se guarda como sofrimento, como perda de si, como exclusão de possibilidades, e pode se mostrar em raiva ou em feridas psicossomáticas muito diversas de pessoa a pessoa. Teicher (2002) assinala que, do ponto de vista da neurobiologia, o abuso deixa também marcas indeléveis no cérebro devido ao estresse experimentado.

Serviço Social \& Saúde, Campinas, v. 2, n. 2, p. 65-82 
Trama intrafamiliar autoritária/ machista abusadora

COMPANHEIRA/

COMPANHEIRO/

MÃE / MADRASTA

PAI / PADRASTO

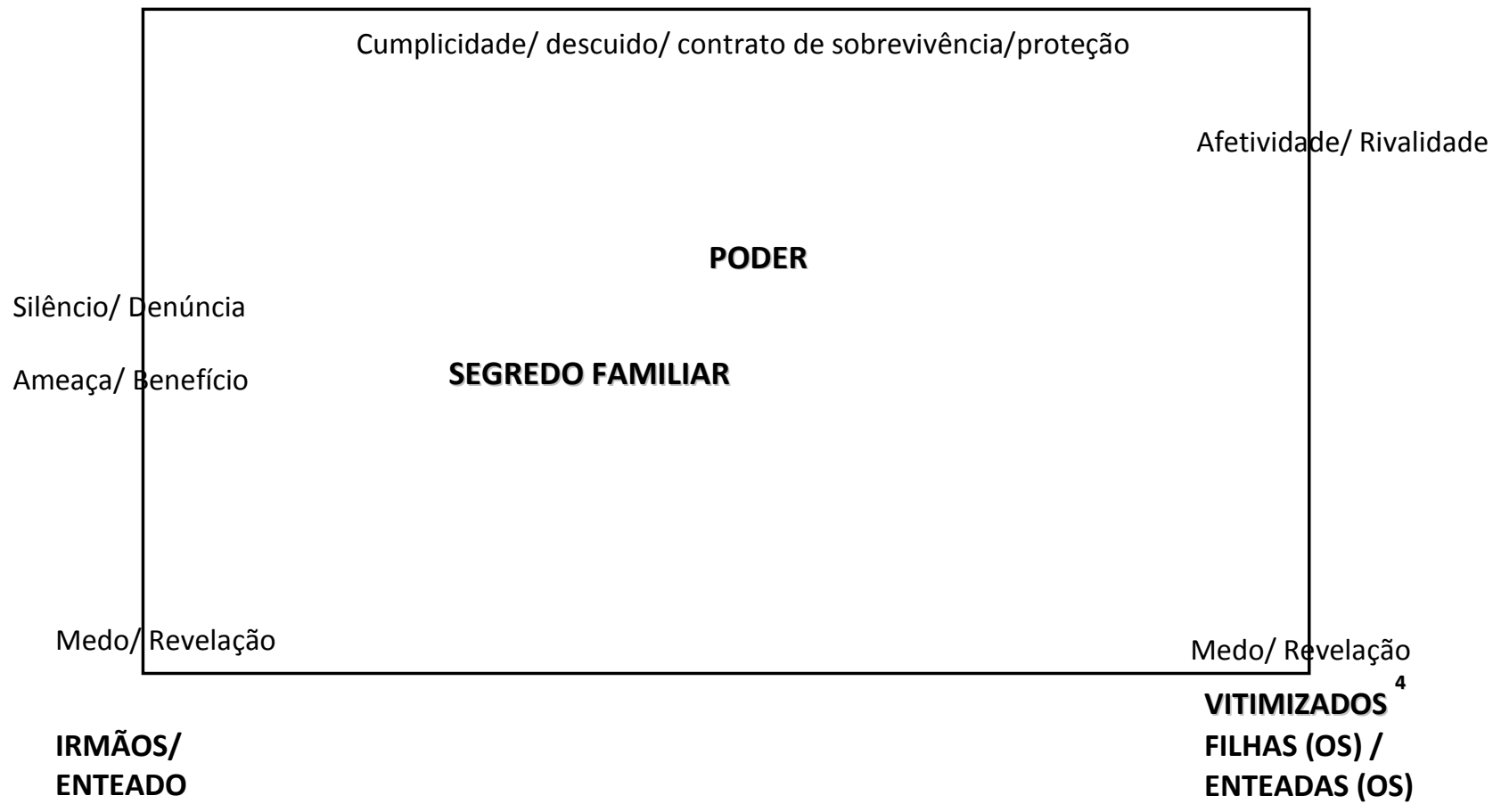

Na realidade do incesto existe uma inversão de papéis sociais e de afetividade. O protetor se torna agressor e o afeto respeitoso destinado ao outro se faz sedução dominadora. Eva Faleiros (2000), seguindo Cohen, conclui pela existência de um comportamento parafílico, ou seja, segundo o dicionário Aurélio, trata-se de um grupo de distúrbios psicossexuais em que o indivíduo sente necessidade imediata, repetida e imperiosa de ter atividades sexuais, em que se incluem, por vezes, fantasias com objeto não humano, auto-sofrimento ou auto-humilhação, ou sofrimento ou humilhação, consentidos ou não, de parceiro. Lazartigues (1995) lembra que o traumatismo vem da intempestividade da ação do abusador, do inesperado, da surpresa, traduzindo atos inconscientes ou conscientes que revelam uma organização psíquica imatura.

Através do incesto ou abuso transgride-se o tabu do imaginário social, as leis e uma relação de proteção e respeito à autonomia da vítima. Nessa transgressão a pessoa vitimizada $^{4}$ (seja do sexo feminino, seja do sexo masculino) não tem a opção e as condições

\footnotetext{
${ }^{4}$ Isolados pelo poder do agressor.

Serviço Social \& Saúde, Campinas, v. 2, n. 2, p. 65-82
} 
de resistir, de dizer não, sendo obrigada/seduzida à passividade. O trauma tem, assim, várias dimensões que podem perdurar mais ou menos profundamente durante o resto da vida da vitimizada ou do vitimizado, por ter havido, de fato, o abuso de uma expectativa de proteção e de respeito, o abuso de um corpo, numa relação forçada pelo mais forte, na violação de um tabu social, do direito, das leis, da proteção e do respeito e que se traduz em raiva, nojo, sofrimento, depressão e comportamentos marcados por desleixo, evasão, agressão, ansiedade, medo, iniciativas sexuais frente a outras crianças, dentre outros (Ver SEBOLD, 1987 e DUARTE; ARBOLEDA , 2000).

O autoritarismo e o machismo são os fundamentos dessa violência, mas há uma relação de cumplicidade e silêncio entre a mãe, o pai/padrasto, os irmãos e enteados e os vitimizados, que tentei desenhar no esquema acima. A relação de violência sexual está centrada nos dois eixos expressos no centro do esquema, que são o segredo familiar e o poder.

O uso deslegitimado do poder (inversão do poder legítimo de proteger) exerce-se, principalmente e em geral, por um membro próximo e reconhecido pela criança como o tio, o pai, o padrasto, o irmão ou um parente próximo. É relativamente rara a violência sexual ser exercida por desconhecidos e é muito mais praticada contra mulheres, envolvendo uma questão de gênero. Irmãos adolescentes têm se mostrado como abusadores, como o revela a réplica da pesquisa relatada em Faleiros e Faleiros (2001) em cinco capitais de diferentes regiões do país ${ }^{5}$.

Em geral, é um conhecido da vítima o que exerce a agressão no processo de violência intrafamiliar. Os maus-tratos físicos, como se sabe, e como é demonstrado em várias pesquisas, são muito mais exercidos pela mãe, e a violência sexual mais presente por parte do pai, do padrasto e mesmo de irmãos ou outros parentes como avós e tios.

Na violência sexual, manifesta-se, como o expressa Heleieth Saffioti (1987), o poder do macho. Esse poder, como vimos, é o maior poder exercido dentro do contexto familiar e se exerce sobre o corpo e a psique da criança. Esta é submetida, pois não tem escolha, ao poder/prazer do mais forte e ao segredo sobre esta relação.

A relação da mãe com o pai ou o padrasto abusador é, por sua vez, uma relação dividida. É uma relação, ao mesmo tempo, de cumplicidade com o abuso ou com o

\footnotetext{
${ }^{5}$ A pesquisa, coordenada por Eva Faleiros, deve ser publicada pelo Ministério da Justiça em 2002 Serviço Social \& Saúde, Campinas, v. 2, n. 2, p. 65-82
} 
abusador e de contrato de sobrevivência e de proteção. O abusador é, ao mesmo tempo próximo e o provedor.

Até mesmo juízes e promotores têm dificuldade em condenar o abusador sexual porque ele representa o papel de provedor da família, cuja prisão também priva a família de sustento. Ao mesmo tempo em que as mães, muitas vezes, se tornam cúmplices, são também, por outro lado, de acordo com as pesquisas, denunciantes do abuso sexual.

$\mathrm{Na}$ pesquisa de Vera Lúcia Pinheiro, do NECASA (Núcleo de Estudos e Atendimento da Criança da Universidade Federal de Goiânia), intitulada "Família, Violência e Silêncio" (2001), onde foram estudadas nove situações de abuso sexual, as/os denunciantes podem ser os vizinhos, a mãe e outros parentes.

Pode-se observar, também, como na nota Rodrigues (2000) que as famílias violentas têm se mostrado famílias abusadoras. Os conflitos do casal também se refletem no momento da revelação, da denúncia e da notificação. A mulher (mãe, avó, tia) tem tido um papel importante na notificação do abuso, mas também manifesta ambigüidade em relação ao pacto do silêncio, em vista da cultura patriarcal e autoritária, mesmo depois de rompido o segredo, como assinala Pinheiro (2000, p. 98): “as descrições feitas pelas meninas e por suas mães acerca dos fatos e comportamentos que se sucederam ao fim do silêncio sobre os abusos sexuais em suas famílias permitem observar que o segredo que os envolvia foi rompido em decorrência dos sintomas manifestados pelas meninas, cujo sofrimento não conteve o silêncio construído pelas mediações de uma educação voltada para a submissão do sujeito. Entretanto, a quebra desse pacto não pressupõe o rompimento com as mediações culturais que tornaram possível o referido segredo. Daí sua reconstituição, processo que ocorreu de forma simultânea à deslegitimação do sofrimento da menina”. Nessas mediações como dissemos, o sujeito se encontra dividido entre o real e o imaginário, entre o lado amoroso e o lado perverso de alguém muito próximo, entre a auto-proteção da família e o escândalo público de se saber da violência que a afeta.

A relação da mãe/madrasta ou companheira com os filhos ou enteados também se apresenta dividida entre afetividade e rivalidade, considerando-se que, ao mesmo tempo que ela quer dar proteção à criança, ela vê na mesma criança uma rival que compete pela afeição do companheiro que pratica o abuso contra essa criança. Assim, fica dividida entre o silêncio obrigado e a denúncia, porque ela se sente angustiada com essa situação. Muitas mães denunciam a situação apesar da ameaça recebida, ela é também ameaçada, com o Serviço Social \& Saúde, Campinas, v. 2, n. 2, p. 65-82 
benefício secundário de se verem livres do peso de conviver com alguém que tem um comportamento inadequado para com os próprios filhos.

Os irmãos ou enteados se vêem também atemorizados, ou não conhecem bem a situação de abuso, e ficam, da mesma forma, divididos entre o medo e a revelação. As vtimizadas e os vitimizados, por sua vez, estão divididos e com medo, porque, em geral, podem ser até ameaçados de morte pelo abusador, no caso de uma possível revelação e sofrem o trauma dessa trama de estarem nas mãos do outro para sua sobrevivência.

No processo de revelação é que, vamos dizer assim, explode o pus da ferida, vem à tona a trama, desfaz-se o segredo, o abusador fica de vez sem autoridade moral, embora, em geral negue e renegue a realidade do abuso. Trata-se de um processo complicado, mas ao mesmo tempo, crucial. A revelação é o momento chave para superação do abuso, para reverter esse tipo de violência sorrateira, em segredo e ameaçadora. Em contraposição, a violência física é, em geral, clara: ela pode se manifestar num grito, no choro.

Essa violência física pode, até mesmo, pressupor uma certa justificativa social: a correção, que se expressa muitas vezes com a frase: "estou te batendo para o teu bem, para te educar, para te ensinar", "para corrigir o erro", conforme bem o demonstrou Miller (1984).A correção física visa a obediência, ou seja, na expressão de Foucault, tornar as pessoas úteis e dóceis e a violência sexual é articulada a uma complexa relação de poder/prazer, consciente ou inconsciente num contexto também complexo de uma família fragilizada por condições sociais inadequadas (como alcoolismo, drogas, promiscuidade, trabalho intenso seja de alto, seja de baixo nível) ou psicossociais como imaturidade, superproteção, rejeição.

No processo de maus tratos (chamados de corretivos) parece que se acentua um hiato entre gerações e uma falta de critérios para a educação dos limites sociais. É comum, na sociedade brasileira, passar-se da agressão ao laissez-faire, estabelecendo-se o que tenho chamado de "disciplina errática". Nesse contexto a agressão é seguida de carícias, como forma de reparação, sem que se tenha um rumo, uma regra civilizatória para se impor limites, explicá-los e fazê-los cumprir. Certos adultos surram ou golpeiam e depois dão um chocolate para a criança, deixando-a com duplo vínculo entre o que é certo e o que é errado, e acentuando-se uma relação incongruente entre punição e culpa. No castigo, assim como na violência sexual culpa-se a vítima (desobediência ou sedução), mas o agressor físico tenta "compensar" ou mascarar sua culpabilização com o afago subseqüente e o Serviço Social \& Saúde, Campinas, v. 2, n. 2, p. 65-82 
agressor sexual com o discurso do prazer que viria proporcionar ou do poder que possa exercer.

Em relação à reparação relativa aos abusos sexuais, Deltaglia (1995) considera que é necessário levar em conta as necessidades e ao atendimento ao trauma da vítima. É necessário ainda considerar seus direitos fundamentais e sociais. $\mathrm{O}$ abusador deve assumir sua responsabilidade pelo mal feito e agir junto à vítima, com a mediação da Justiça, do meio, dos profissionais. Esta mediação passa pela sanção, pelo perdão, pela reparação material e eliminação de novas agressões. Madanes (1997) também acentua a possibilidade de reparação, principalmente através do uso da mediação do terapeuta para o arrependimento do abusador.

Na violência sexual, existe também por parte do abusador, uma relação dividida entre a sedução e prazer e a agressão. Não é raro o enredo ou a trama do abuso realizar-se em um ritual, que, muitas vezes, se opera quando o abusador espreita a vítima para fazê-la cair na armadilha da sedução ou da ameaça. Busca ressaltar ou fazer aparecer que a vítima é sua preferida ou o preferido e também "linda" (o), "sedutora" (or), "gostosa" (o). O abusador também oferece presentes, doces ou guloseimas para as vítimas e, paradoxalmente, não se vê violento.

A saída dessa relação de violência é muito complexa, passa pela sua revelação no interior da família, para desfazer-se a trama, explicitar o drama e curar o trauma.

Junto à família dividida vai ser necessário trabalhar-se, profissionalmente, esta mesma divisão que se manifesta no interior da família, uns sendo a favor, outros contra a revelação, outros indiferentes e com medo de explicitá-la, com medo do agressor.

Para que se venha a falar e a superar o medo é preciso ter portas de entrada seguras, seja um telefone SOS, mas onde exista acolhida, investigação serena, resolubilidade.A rede de proteção precisa funcionar como o inverso da trama abusadora, ou seja como uma rede de proteção: com preeminência para a palavra da vítima, da mulher, com acolhida, com respeito e serenidade.

É preciso um espaço aberto para se trabalhar a revelação, com a expressão e a compreensão do que acontece, pois, o fato é percebido, muitas vezes, como “inacreditável”, segundo os depoimentos acima citados. Ao se expor o drama é preciso ter cuidado para não se reviver o trauma, a revitimização, o sofrimento. Os depoimentos das vítimas, além de 
terem a garantia do respeito precisam ser expostos o menos possível, acreditando-se em sua palavra.

A busca de provas, como se mostra na pesquisa "Circuitos e curtos-circuitos" de Faleiros e Faleiros (Veras Editora, 2001) deve levar em conta que o crime de abuso sexual não deixa marcas sempre visíveis, e quando existem, são fugazes. A ameaça de incesto envolve toda a família e sua capacidade de indignar contra a violência, assinala Lempert (1995)

A rede primária, da família, que se apresenta dividida, por isso mesmo, precisa ser trabalhada quanto às possibilidades de se reconstruir a proteção, com a articulação de relacionamentos positivos que venham efetivamente proteger a criança.

No livro citado referimo-nos à rede de vizinhança, que se mostra também contraditória, pois os vizinhos, às vezes estão envolvidos na trama do abuso, seja conhecendo-o, mas com medo de denunciar ou com receio de se envolver em questões alheias, seja reagindo com indignação, mas sem saber como agir.

As discussões comunitárias, as discussões com jovens, as informações através de folhetos, dos professores precisam ser objetivas e corretas e não moralizantes ou demonizadas (que muitas vezes só apresentam o abusador como diabo ou monstro) e podem abrir espaço para uma visão da complexidade da questão, para a revelação, a denúncia familiar ou social e a notificação formal.

Pinheiro (2001) assinala que surgem situações em que a família faz um pacto de silêncio entre si, não antes, mas depois da revelação, para os vizinhos não saberem do abuso. A família busca proteger seus membros, inclusive abusadores.Mas há situações bem diferentes, fundadas na divisão de que falamos acima, pois parte ou a maioria da família não aceitam o abuso e nem o abusador.

A ação da família e da rede implicam três dimensões a que nos referimos no livro citado (Faleiros e Faleiros, 2001): o atendimento, a responsabilização e a defesa. A pessoa vitimizada precisa de atendimento para enfrentar o trauma, com acesso a profissionais competentes e capazes de deslindar a questão numa perspectiva evolutiva e emancipatória, seja com a redução dos danos seja com a redução dos riscos. Danos e riscos se conjugam num processo complexo pois é preciso diminuir riscos que implicam a ausência ou distância do abusador, como também mudanças objetivas no convívio familiar e em suas condições de vida. O empoderamento ou empowerment da vítima implica o Serviço Social \& Saúde, Campinas, v. 2, n. 2, p. 65-82 
desenvolvimento de seu capital social cognitivo, emocional, social, afetivo (Ver Faleiros, 1997)

A proteção e o atendimento é que se ocupam, então, das pessoas, da dor, do dano, do dar acesso aos direitos, às políticas sociais de proteção, à prestação serviços de assistência e saúde, ao do cuidar e ao proteger.

A responsabilização é o processo legal de notificação, de investigação, de denúncia pública, de processo jurídico, de sanção e de penalização (condenação) do abusador. Ela se focaliza no abusador e na sua responsabilização social e legal pela transgressão efetivada. As ações contra o abusador são de natureza privada, exceto se quando as vítimas forem pobres (sem poder arcar com as despesas do processo sem ferir a subsistência), o autor do delito for o pai, padrasto, tutor ou curador da vítima, ou ainda quando a vítima sofra lesão corporal ou morra (Luiza Nagib Eluf, in Folha de São Paulo de 05/04/02, pg. A-3).

Infelizmente, é praticamente inexistente no Brasil o atendimento e o tratamento do abusador - em alguns países também se admite o tratamento como pena. Também se pode valorizar a reparação, como vimos acima $\mathrm{O}$ abusador muitas vezes é submetido a sevícias na cadeia e muitos, depois da prisão, voltam a cometer os mesmos crimes.

O fluxo de defesa compreende a defesa dos direitos, da garantia e da cidadania, da palavra da vítima, de seus direitos, fortalecidos principalmente pelo Conselho Tutelar, pelo Ministério Público e Centros de Defesa. O apoio a mulheres ameaçadas e a testemunhas pode ser fundamental nesses casos.

Tanto na prevenção, quanto na responsabilização como no atendimento, a expressão do drama, o desfazimento da trama e o enfrentamento do trauma se descontroem e constroem, como vimos na pesquisa dos Curtos-Circuitos, através da palavra do vitimizado e da vitimizada e da comunicação aberta com esta palavra. É através da palavra que vamos poder trabalhar todo o cuidado, ela é o centro da revelação do segredo e do desmonte do poder.

No circuito do atendimento temos a presença de instituições executoras das políticas sociais: saúde, educação, assistência, trabalho, cultura, lazer, profissionalização, serviços e programas de proteção especial, bem como as ONGs que atuam nessas áreas. Essas políticas precisam estar articuladas, trabalhando em rede, com eficiência, com profissionais disponíveis. As políticas de apoio à revelação, de abrigo, de cuidados, de prevenção, de Serviço Social \& Saúde, Campinas, v. 2, n. 2, p. 65-82 
informação, de aconselhamento precisam estar, pelo menos, integradas. Pensar além da integração implica a construção social de redes efetivas, com responsabilidades, recursos e poderes compartilhados que se constroem através de um pacto de estratégias públicas ao invés do pacto do silêncio da violência.

No circuito da responsabilização, temos as Delegacias, o Instituto Médico Legal, as Varas da Justiça e o Ministério Público, órgãos responsáveis pela investigação, pela prisão, pelo julgamento, controle, execução e sanção do abusador.

É preciso romper com a ruptura dos dois circuitos, o do atendimento e o da responsabilização que, em geral, funcionam separadamente, em corredores paralelos. É preciso dar passos concretos e progressivos, por exemplo, colocando-se esta questão na agenda de cada instituição ou organização como na assistência social, na saúde, na educação, no Judiciário, na Polícia, para citar um grupo que pode ser um ponto de partida de mobilização para a proteção.

A integração operacional pode ser efetivada mais profundamente e a curto prazo, entre assistência, saúde e polícia, para ir se ampliando em discussões periódicas. A experiência da CIRCO (Comissão Interestadual pelo Fim da Violência Sexual no CentroOeste) tem trazido valiosos elementos para uma política de integração das ações do Estado e da sociedade, de acordo com o Sistema de garantias do Estatuto da Criança e do Adolescente (ECA).

$\mathrm{Na}$ rede de defesa, os conselhos tutelares são instrumentos fundamentais para se poder zelar pelos direitos da criança. São os olhos e a potencialização da voz das próprias crianças e das denúncias para enfrentamento da trama, do drama e do trauma.

As instituições e os profissionais precisam olhar a questão da violência sexual, essa trama, esse drama, esse trauma enquanto fluxo e enquanto rede e não enquanto normas burocráticas, para se trabalhar além da interdisciplinaridade, ou seja, em rede e processualmente.

Como mostra a pesquisa citada (FALEIROS, FALEIROS, 2001) a responsabilização do abusador tem sido acionada, sem os resultados esperados frente à complexidade de atores que intervêm na questão, mas o fluxo de atendimento simplesmente não funciona, seja pelas condições das próprias organizações, seja pelas condições das vítimas, entre as quais não poder pagar uma passagem de ônibus ou pelas condições de desigualdade social desse país.

Serviço Social \& Saúde, Campinas, v. 2, n. 2, p. 65-82 
Em síntese, é necessário um paradigma de pensamento e ação fundados na defesa dos direitos humanos e na complexidade da questão da violência sexual e da sexualidade, da família e de seu contexto, das redes em sua articulação para se enfrentar o abuso sexual incestuoso ou não na agenda das estratégias de ação, buscando incessantemente a intervenção em rede como fluxo integrado da responsabilização, do atendimento, da defesa dos direitos, da prevenção e da vivência de uma sexualidade saudável e protegida.

\section{BIBLIOGRAFIA}

ARENDT, H. Da violência. Brasília, Editora da UnB, 1985

COHEN, C. O incesto. Um desejo. Casa do Psicólogo Livraria e Editora Limitada, São Paulo. 1993.

COSTA, J. de J. da (Coord.) Rompendo o silêncio. Seminário multiprofissional de capacitação sobre abuso e exploração sexual de crianças e adolescentes. CDCA, Centro de Defesa Pe. Marcos Passerini/Procuradoria Geral da Justiça, São Luis, 1997.

DELTAGLIA, L. La Réparation des Abus Sexuels, in CASTRO, D. (sous la direction), Incestes. Paris, L'Esprit du Temps, 1995, p. 351-357.

DIDIER-WEILL, A.. Caïn, l’homme furieux. In: DANZIGER, C. Violences des familles. Paris, Autrement, 1997, p.17-21

DUARTE, J. C.; ARBOLEDA, M. D. R. C. (2000). El abuso sexual infantil: um grave problema social. In DUARTE, J. C.; ARBOLEDA, M. D. R. C. (Orgs). Guía para la evalución del abuso sexual infantil. Madrid, Pirámide.

FALEIROS, E. T. S. (2000) Repensando os Conceitos de Violência, Abuso e Exploração Sexual de Crianças e de Adolescentes. MJ/DCA/UNICEF/VISÃO MUNDIAL/CECRIA. Brasília.

FALEIROS, V. de P.; FALEIROS, E. T. S. (2001). Circuito e curtos-circuitos. Atendimento, defesa e responsabilização do abuso sexual contra crianças e adolescentes.São Paulo, Veras Editora

FALEIROS, V. de P. (1997) Estratégias em Serviço Social. São Paulo, Cortez

FALEIROS, V. de P. (1998) Redes de Exploração e Abuso Sexual e Redes de Proteção. Brasília, Anais do VIII Congresso Nacional de Assistentes Sociais, Goiânia. Serviço Social \& Saúde, Campinas, v. 2, n. 2, p. 65-82 
FALEIROS, V. de P. A questão da violência. In: SOUSA, Jr. J. G. et al. Educando para os direitos humanos. Porto Alegre, Síntese, 2004, p. 83-98

LAZARTIGUES, A. (1995) Quand 1'inceste devient réalité. In: CASTRO, D. (sous la direction) Incestes. L'Esprit du Temps. Paris, p. 49-70

LEMPERT, B. (1995). La menace incestueuse. In: CASTRO, D. (sous la direction) (1995) Incestes. L’Esprit du Temps. Paris

MADANES, Cloé (1997) Sexo, amor e violência - Estratégias para a transformação. Campinas/SP, Editorial Psy

MILlER, A. (1984) C’est por ton bie. Racines de la violence dans l'éducation de l'enfant.Paris, Aubier

PINHEIRO, V. L. (2001). Família, Violência e Silêncio. NECASA. Núcleo de Estudos e Atendimento da Criança da Universidade Federal de Goiânia. Dissertação de Mestrado

RODRIGUES, A. A. (2000). A violência doméstica contra crianças e adolescentes: a análise da realidade no Distrito Federal a partir do atendimento realizado pelo SOS Criança no período 1997/1998. Brasília, UnB, Pós-Graduação em Política Social, Dissertação de Mestrado

SAFFIOTI, H. I. B. O poder do macho. São Paulo: Moderna, 1987.

SEBOLD, J. (1987) Indicators of child sexual abuse in males. Special Issue: Child sexual abuse". Social Casework, 1987, Feb Vol. 68 (2), pp. 75-80 (in Orchard Place Treatment Ctr, Des Moines, IA). Traduzido por Edileusa Rocha, revisado por Vicente Faleiros e Eva Silveira Faleiros.

TEICHER, M. H. (2002). Feridas que não cicatrizam: a neurobiologia do abuso infantil. In www.sciam.com.br 